\title{
REVIEW \\ Developing a spinal cord injury research strategy using a structured process of evidence review and stakeholder dialogue. Part I: rapid review of SCI prioritisation literature
}

\author{
P Bragge $^{1}$, L Piccenna ${ }^{1}$, JW Middleton ${ }^{2}$, S Williams ${ }^{3}$, G Creasey ${ }^{4}$, S Dunlop ${ }^{5}$, D Brown ${ }^{6}$ and RL Gruen ${ }^{7,8}$
}

Study design: This is a rapid evidence review.

Objectives: The objective of this study was to gain an overview of the volume, nature and findings of studies regarding priorities for spinal cord injury $(\mathrm{SCl})$ research.

Setting: A worldwide literature search was conducted.

Methods: Six medical literature databases and Google Scholar were searched for reviews in which the primary aim was to identify $\mathrm{SCl}$ research priorities.

Results: Two systematic reviews were identified —one of quantitative and one of qualitative studies. The quality of the reviews was variable. Collectively, the reviews identified 31 primary studies; 24 quantitative studies totalling 5262 participants and 7 qualitative studies totalling 120 participants. Despite the difference in research paradigms, there was convergence in review findings in the areas of body impairments and relationships. The vast majority of literature within the reviews focused on the $\mathrm{SCl}$ patient perspective.

Conclusion: The reviews inform specific research topics and highlight other important research considerations, most notably those pertaining to $\mathrm{SCl}$ patients' perspectives on quality of life, which may be of use in determining meaningful research outcome measures. The views of other $\mathrm{SCl}$ research stakeholders such as researchers, clinicians, policymakers, funders and carers would help shape a bigger picture of $\mathrm{SCl}$ research priorities, ultimately optimising research outputs and translation into clinical practice and health policy change. Review findings informed subsequent activities in developing a regional SCl research strategy, as described in two companion papers.

Sponsorship: This project was funded by the Victorian Transport Accident Commission and the Australian and New Zealand SCI Network.

Spinal Cord (2015) 53, 714-720; doi:10.1038/sc.2015.85; published online 23 June 2015

\section{INTRODUCTION}

Spinal cord injury (SCI) affects many individuals across the world. The annual incidence of traumatic SCI is estimated to range between 12.1 and 57.8 per million worldwide, ${ }^{1}$ and SCI rates vary between countries and across regions - in North America (39 per million), Western Europe (16 per million), Australia (15 per million) and in New Zealand (30-49 per million). ${ }^{2,3}$ In Australia, this equates to around 285 new acute traumatic SCIs per year, predominantly from transportrelated accidents (46\%) and falls (28\%), with tetraplegia (53\%) slightly more frequent than paraplegia and the majority of cases involving males, with a male to female injury ratio of $5.3: 1 .{ }^{4}$ Non-traumatic SCI adds to these figures; an Australian study reported an age-adjusted adult incidence rate of 26.3 cases per million per year. ${ }^{5} \mathrm{SCI}$ prevalence is estimated to be 10-12 000 traumatic and 8000 non-traumatic cases in Australia. ${ }^{6,7}$

Sensorimotor and autonomic nervous system dysfunction following SCI results in a range of acute, rehabilitation and long-term healthcare challenges, including pressure injuries, disorders of muscle tone and bowel and bladder problems. ${ }^{8}$ These sequelae have long-term effects on independence and psychological well-being post SCI. ${ }^{9}$ Aside from the potentially devastating impact of traumatic SCI on physical function, social participation and quality of life, traumatic SCI carries a high financial cost, estimated in Australia to be $\$ 2$ billion annually, or $\$ 5$ million per case of paraplegia and $\$ 9.5$ million per case of tetraplegia. ${ }^{6}$

Research prioritisation has become an area of interest in recent years, owing to a high demand for evidence-based resources combined with limited research resources. ${ }^{10,11}$ Research prioritisation is of particular importance in SCI, given that the breadth of challenges experienced by people after SCI presents multiple potential avenues of enquiry. The process of prioritising research is complex. There are numerous prioritisation criteria including clinical importance/magnitude of problem, likelihood of reducing burden, cost-effectiveness, present knowledge, resources, ethical aspects, research capacity, novelty and controversy. ${ }^{12,13}$ These can be broadly categorised into

${ }^{1}$ National Trauma Research Institute, Monash University and The Alfred Hospital, Melbourne, Victoria, Australia; ${ }^{2} \mathrm{John}$ Walsh Centre for Rehabilitation Research, The University of Sydney, Sydney, New South Wales, Australia; ${ }^{3}$ The Spinal Cord Injury Network, Sydney, New South Wales, Australia; ${ }^{4}$ Department of Neurosurgery, Stanford University School of Medicine, Stanford, CA, USA; ${ }^{5}$ Experimental \& Regenerative Neuroscience, School of Animal Biology, The University of Western Australia, Crawley, Western Australia, Australia; ${ }^{6}$ Spinal Research Institute, Melbourne, Victoria, Australia; ${ }^{7}$ Monash University, Melbourne, Victoria, Australia and ${ }^{8}$ Lee Kong Chian School of Medicine, Nanyang Technological University, Singapore

Correspondence: Dr P Bragge, National Trauma Research Institute, Monash University and The Alfred Hospital, Level 4, 89 Commercial Road, Melbourne, Victoria 3004, Australia.

E-mail: peter.bragge@monash.edu

Received 1 December 2014; revised 21 January 2015; accepted 16 February 2015; published online 23 June 2015 
three key domains: public health benefit (should we do it?); feasibility (can we do it?); and cost. ${ }^{12}$ There are also multiple methods for deciding on priorities as outlined by Viergever et al., 12 which can be classified broadly into consensus-based approaches (driven by stakeholder input), metrics-based approaches (for example, the Delphi technique) and combination approaches (for example, prioritisation followed by discussion using a nominal group approach). Two recent examples of SCI research prioritisation are Guest et al.'s ${ }^{14}$ description of the prioritisation process followed by the North American Clinical Trials Network, which is based on earlier work by Kwon et al. ${ }^{15,16}$ who developed a scoring system for grading pre-clinical literature on neuroprotective treatments for acute SCI.

The purpose of this review was to gain an overview of the volume, nature and findings of studies that aimed to identify priorities for SCI research. This was undertaken as part of a structured process of evidence synthesis (rapid review) and stakeholder consultation (expert opinion) to develop a regional (Australia and New Zealand) SCI research strategy. Two companion papers describe subsequent steps in the process. ${ }^{60,61}$

\section{MATERIALS AND METHODS}

The review used a rapid review methodology. Rapid reviews are an emerging method of efficiently synthesising research evidence in settings such as health policymaking, in which a broad overview of evidence is required in a short time frame, for example, 5 weeks, rather than the 6-24 months required for a systematic review (SR). Rapid reviews are primarily distinguished from SRs by their focus on searching for and summarising synthesised research evidence (that is, relevant reviews) and, where these are not available, high-quality or recent primary studies. ${ }^{17}$

\section{Search strategy}

A comprehensive search of the following databases (from initiation until 31 October 2012) was undertaken: Medline (1950-31 October 2012; see Appendix 1); All EBM (All EBM Reviews: the Cochrane Database of Systematic Reviews, ACP Journal Club, Database of Abstracts of Reviews of Effects (Cochrane methodology register, Health technology assessment, NHS economic evaluation database) and the Cochrane Central Register of Controlled Trials.); CINAHL; PsycINFO; EMBASE; and Web of Science. Google Scholar was also searched using the terms 'spinal cord injury' combined with 'research priorities' with no date restriction. The first 100 results from the Google Scholar search were screened. Reference lists of included studies were also scanned to identify further relevant references.

\section{Inclusion criteria}

Identified citations and full text studies were screened against the following inclusion and exclusion criteria: this was conducted by two authors (LP and PB). An initial $10 \%$ of the screening was performed by both authors independently in order to refine interpretation of the inclusion and exclusion criteria.

Inclusion criteria:

- Population: key stakeholders in SCI research: patients, patient representatives, families and carers; researchers (all types of research); clinicians (all phases of SCI care); policymakers; research funders; and representatives of healthcare organisations.

- Intervention: any project in which the primary aim was to identify research priorities, or priorities that can be addressed by research, through direct engagement with the above population. Project methods could be qualitative or quantitative (for example, survey).

- Study type: SRs, defined as ' ....an overview of primary studies which contains an explicit statement of objectives, materials and methods and has been conducted according to explicit and reproducible methodology. ${ }^{, 18}$ p. 672.

- Publication status: published in peer-reviewed journals.

\section{Exclusion criteria}

- Primary studies or reviews in which there is no direct engagement with the population of interest. SRs often contain discussion regarding future research priorities, however, these are influenced by review scope and reflect primarily the views of the review authors.

- Studies examining research priorities within a specified area of SCI (for example, pressure ulcers, bladder care), because the review focus was the entire field of SCI.

\section{Quality appraisal}

Quantitative studies collect and analyse numerical or categorical data, whereas qualitative research emphasises in-depth exploration and description rather than numerical measurement. ${ }^{19}$ Therefore, different methods are used to both review and evaluate reviews of quantitative and qualitative literature. Eligible quantitative SRs were critically appraised using the AMSTAR tool (http://amstar.ca/), an 11-item tool with well-established validity and reliability that is extensively used to evaluate quantitative SRs. ${ }^{20-22}$ Critical appraisal of qualitative studies is an area of ongoing debate, and currently there is no consensus on an appropriate critical appraisal tool for qualitative research, and researchers are advised to choose a tool specific to this research paradigm. ${ }^{23}$ Therefore, eligible qualitative SRs were critically appraised using five criteria designed to evaluate the rigor of qualitative reviews. ${ }^{24}$ The 11 AMSTAR items and the five qualitative review evaluation criteria, as well as the results of quality appraisal, are contained in Appendix 2. All critical appraisal was carried out by one of the authors (LP).

\section{RESULTS}

The search of electronic databases yielded 293 articles. Two reviews met the selection criteria: one SR of quantitative studies ${ }^{25}$ and one meta-synthesis of qualitative studies. ${ }^{26}$ The SR of quantitative studies ${ }^{25}$ was rated as being of low-to-moderate methodological quality; a key shortcoming of this review was lack of quality appraisal of the included studies, which may bias review findings and conclusions. The metasynthesis of qualitative studies ${ }^{26}$ was rated as being of high methodological quality, fulfilling all quality assessment criteria (Appendix 2).

Table 1 presents a summary of review characteristics. Table 2 lists the primary review findings, highlighting areas of overlap and the authors' conclusions. Table 2 shows that all of the priorities identified by Simpson et al. ${ }^{25}$ were encompassed within the themes identified by Hammell. ${ }^{26}$ Specifically, the four 'function' themes in Simpson et al. relate to concepts 1 and 2 in Hammell; themes 5 and 6 from Simpson et al. relate to concepts 3 and 4 in Hammell; and the remaining concepts in Hammell are not directly relatable to any of the themes from Simpson et al. Characteristics of the studies included in the two reviews (citation, number of participants, data collection method and population) are contained in Appendix 3. Of the 31 included studies within the two reviews, only one ${ }^{27}$ study involved participants other than people with an SCI. A further two relevant primary studies were identified that had not been included in the reviews, ${ }^{28,29}$ which also engaged solely with people with a SCI.

\section{DISCUSSION}

This is the first known overview of reviews examining research priorities in the field of SCI. The rapid review approach is less comprehensive and robust than a SR. This means that caution needs to be applied when interpreting review findings, as deeper exploration of primary literature may elucidate further insights and therefore influence interpretation of review findings. However, rapid reviews, because of their timeliness, have a number of potential uses:

- 'to serve as an informative brief that prepares stakeholders for discussion on a policy issue; 
Table 1 Summary of included systematic reviews

\begin{tabular}{|c|c|c|}
\hline Citation & Simpson et al..25 & HammelR6 \\
\hline $\begin{array}{l}\text { Review type and } \\
\text { aim }\end{array}$ & $\begin{array}{l}\text { Systematic review of quantitative studies 'that directly surveyed } \\
\text { people with SCI to ascertain their health priorities and life } \\
\text { domains of importance.' (p. 1548). }\end{array}$ & $\begin{array}{l}\text { Systematic review of qualitative studies 'To identify, compare and } \\
\text { synthesize the factors found to contribute to, or detract from the experience } \\
\text { of a life worth living following spinal cord injury (SCI).' (p. 124). }\end{array}$ \\
\hline Inclusion criteria & $\begin{array}{l}\text { - Studies of individuals with } \mathrm{SCI} \text { who were } 17 \text { years of age or older; } \\
\text { - Obtained the perceived priorities, needs and important domains by } \\
\text { direct questioning; } \\
\text { - Reported SCI specific data; } \\
\text { - Published in a peer-reviewed journal. }\end{array}$ & $\begin{array}{l}\text { - Qualitative studies assessing determinants of Quality of Life for people } \\
\text { with SCl living in the community. } \\
\text { - Studies that 'included participants' words to support the researchers' } \\
\text { interpretations' (p. 126) and met pre-determined criteria for qualitative rigor. }\end{array}$ \\
\hline Exclusion criteria & $\begin{array}{l}\text { - Samples wholly comprising individuals with non-traumatic } \mathrm{SCl} \text {; } \\
\text { - Articles that ascertained the domains of importance to QoL through } \\
\text { statistical analysis of the relationships between different measures (that is } \\
\text { cross-sectional studies using functional and QoL measures, as opposed to } \\
\text { direct questioning or self-report); } \\
\text { - Studies examining relationship between interventions to QoL; } \\
\text { - Studies using a qualitative design; } \\
\text { - Conference proceedings; and } \\
\text { - Studies with sample less than } 10 \text {. }\end{array}$ & $\begin{array}{l}\text { - Studies undertaken outside the context of the 'Western' (minority) world } \\
\text { - Study sample not exclusively spinal cord injured. }\end{array}$ \\
\hline $\begin{array}{l}\text { No. studies/ } \\
\text { patients }\end{array}$ & $24 / 5262$ & $7 / 120$ \\
\hline
\end{tabular}

Abbreviations: QoL, quality of life ; SCl, spinal cord injury

- to support the direction and evidence-base for various health policy initiatives; and

- to support the development of clinical interventions and/or health services programs.' (Khangura et al. p. 2). ${ }^{17}$

These uses aligned well with the overarching purpose of this project. Specifically, the findings of this rapid review were used to inform subsequent steps in the development of a regional SCI research strategy, as described in two companion papers. ${ }^{60,61}$

Synthesis of the findings from these reviews is challenging, as they were conducted on separate bodies of literature, using different research paradigms. The reviews had to be evaluated with separate quality appraisal tools for quantitative and qualitative research synthesis (Appendix 2), meaning that a direct comparison of the results of quality appraisal is not possible. Notwithstanding the important differences in study methodology between the included reviews, there was some convergence in review findings. Simpson et al. ${ }^{25}$ noted that Hammell's qualitative review ${ }^{26}$ identified ' $6 / 10$ themes directly related to physical, social and psychological areas' (p. 1554). These are not specified, but two themes from Hammell's review appear directly comparable to the priorities highlighted by Simpson: 'problems associated with an impaired body,' and 'renewed importance of relationships.' This convergence of review findings is interesting in the context that the reviews were published 5 years apart. This could suggest that priorities identified in Hammell's review ${ }^{26}$ have not been fully addressed by subsequent research, and it raises the question of how identified priorities can be (or are being) fed into the research process.

Another way to interpret the results of these reviews is to view them as contributing complementary perspectives. Quantitative studies offer greater explanatory power as they generally involve larger cohorts, whereas qualitative studies provide a more in-depth examination of issues through exploratory interviews on smaller cohorts. Simpson et al.'s review of 24 quantitative studies with a combined sample of over 5000 participants highlights four areas of function-bowel, bladder, sexual and motor-and two life domains-health and relationships. The authors of this review conclude that this information can inform research planning by helping to align consumer and researcher priorities. ${ }^{25}$ Hammell's ${ }^{26}$ qualitative review of 7 studies with a combined sample of 120 participants and a focus on exploration of factors that influence Quality of Life offers 'a more nuanced understanding of the experience of Quality of Life SCI than is achievable by quantitative methods' (p. 136). Specifically, qualitative exploration facilitates description of important concepts associated with adjustment following SCI such as self-worth, injury and loss, and development of new values and perspectives. It also enables relationships between identified priorities to be elucidated. Such information can not only inform the choice of research topics but can also be valuable in different ways for research planning-for example, to identify outcome measures that are meaningful to people with a SCI, regardless of research topic. Future primary studies could incorporate mixed qualitative and quantitative methods in order to harness the complementary information gathered by these approaches.

This review found that only 1 of 31 primary studies examining SCI research priorities included participants other than people with an SCI. Harmonising the lived experience of SCI with research, clinical, policy and other inputs ensures the development of robust, feasible and high-quality research that is more likely to ultimately translate to clinical practice and health policy change. For example, pressure injuries are not among the highest priorities identified by people with SCI. However, severe pressure injuries carry a high burden for both people with SCI and the wider healthcare system. Therefore, pressure injuries may be considered a higher research priority from a clinical and health economics perspective. This illustrates the importance of identifying and balancing multiple perspectives when framing a strategic research agenda.

In addition to gathering the perspectives of people with SCI on research priorities, future studies should also involve other relevant SCI research stakeholders including carers, clinicians, researchers, policymakers and research funders. To this end, we brought together 
Table 2 Findings of eligible systematic reviews illustrating areas of convergence

\author{
1. Bowel function \\ 2. Bladder function \\ 3. Motor function \\ - Arm/hand for people with tetraplegia \\ - Mobility for people with paraplegia \\ 4. Sexual function \\ 5. Health (psychological and physical) \\ 6. Relationships with family and friends
}

Findings of review of quantitative studies by Simpson et al. ${ }^{25}$

Six areas-four areas of function and two life domains- were considered as priorities by individuals with $\mathrm{SCl}$ across the reviewed studies

Findings of eview of qualitative studies by HammelR6

Ten main concepts were identified across the included studies (reproduced from Table 4, (p. 133)

1. Problems associated with an impaired body

2. Injury and loss

3. Renewed importance of relationships

4. Environment: physical, economic, political, legal, social, cultural

5. Assuming responsibility and seizing control

6. Importance of engaging in, and contributing through occupation

7. Development of new values and perspectives

8. Self-worth

9. Continuity of biography

10. Good days and bad day

\section{Authors' conclusions}

'The information from this study, which identified the priorities and domains of importance for individuals with $\mathrm{SCl}$, may be useful for informing health care and research agenda-setting activities.' (p. 1548). 'As consumer priorities and expectations have been identified as a major component of subjective quality of life, consistency between research and consumer priorities is an important goal.' (p. 1554).

Abbreviations: QOL, quality of life; SCI, spinal cord injury.

a representative group of these stakeholders to determine an overarching SCI research strategy that addresses how best to prioritise, plan and successfully undertake SCI research so that its benefits can be fully realised for those living with SCI. This work is described in two companion papers to this review-one outlining the background materials and methods ${ }^{60}$ and one presenting the results of a day-long stakeholder dialogue that deliberated upon these issues. ${ }^{61}$

\section{CONFLICT OF INTEREST}

The authors declare no conflict of interest.

\section{ACKNOWLEDGEMENTS}

We gratefully acknowledge the following people for their generous contribution to this project: Dr Naomi Kleitman, Craig H. Neilson Foundation, CA, USA; John Walsh AM, Magoo Actuarial Consulting, Sydney, New South Wales, Australia; Pam Draganovic, La Trobe University, Melbourne, Victoria, Australia; and Emma Donoghue, Melbourne, Victoria, Australia. This project was funded by the Victorian Transport Accident Commission and the Australian and New Zealand SCI Network.

1 van den Berg ME, Castellote JM, de Pedro-Cuesta J, Mahillo-Fernandez I. Survival after spinal cord injury: a systematic review. J Neurotrauma 2010; 27: 1517-1528.

2 Derrett S, Beaver C, Sullivan MJ, Herbison GP, Acland R, Paul C. Traumatic and nontraumatic spinal cord impairment in New Zealand: incidence and characteristics of people admitted to spinal units. Inj Prev 2012; 18: 343-346.
'QOL was found to be diminished by problems associated with the impaired body; and by a sense of loss. The experience of a life worth living (QOL) was found to be enhanced by meaningful relationships; the assumption of responsibility for, and opportunity to exert control over, one's own life; and the ability to engage in personally meaningful occupations. The review also identified the importance of developing new values and perspectives (by which good and bad days could be viewed as 'normal'); the importance of reconstructing a positive sense of self-worth; and of attaining a sense of biographical continuity' (p. 136).
3 Lee BB, Cripps RA, Fitzharris M, Wing PC. The global map for traumatic spinal cord injury epidemiology: update 2011, global incidence rate. Spinal Cord 2013; 52 . 110-116.

4 AlHW, Norton L. Spinal cord injury, Australia 2007-08. Injury research and statistics series no. 52. Australian Institute of Health and Welfare: Canberra 2010

5 New PW, Sundararajan V. Incidence of non-traumatic spinal cord injury in Victoria, Australia: a population-based study and literature review. Spinal Cord 2008; 46: 406-411.

6 Access Economics. The economic cost of spinal cord injury and traumatic brain injury in Australia. Report by Access Economics Pty Limited for The Victorian Neurotrauma Initiative. 2009: 115 pages.

7 New PW, Farry A, Baxter D, Noonan VK. Prevalence of non-traumatic spinal cord injury in Victoria, Australia. Spinal Cord 2013; 51: 99-102.

8 McDonald JW, Sadowsky C. Spinal-cord injury. Lancet 2002; 359: 417-425.

9 Ackery A, Tator C, Krassioukov A. A global perspective on spinal cord injury epidemiology. J Neurotrauma 2004; 21: 1355-1370.

10 Jaramillo A, Welch VA, Ueffing E, Gruen RL, Bragge P, Lyddiatt A et al. Prevention and self-management interventions are top priorities for osteoarthritis systematic reviews. $J$ of Clin Epidemiol 2013; 66: 503-510.

11 Clavisi O, Bragge P, Tavender E, Turner T, Gruen RL. Effective stakeholder participation in setting research priorities using a Global Evidence Mapping approach. J Clin Epidemiol 2013; 66: 496-502.

12 Viergever RF, Olifson S, Ghaffar A, Terry RF. A checklist for health research priority setting: nine common themes of good practice. Health Res Policy Syst 2010; 8: 36.

13 Bragge P, Clavisi O, Turner T, Tavender E, Collie A, Gruen RL. The Global Evidence Mapping Initiative: scoping research in broad topic areas. BMC Med Res Methodol 2011; 11: 92.

14 Guest J, Harrop JS, Aarabi B, Grossman RG, Fawcett JW, Fehlings MG et al. Optimization of the decision-making process for the selection of therapeutics to undergo clinical testing for spinal cord injury in the North American Clinical Trials Network. J Neurosurg Spine 2012; 17: 94-101.

15 Kwon BK, Okon EB, Tsai E, Beattie MS, Bresnahan JC, Magnuson DK et al. A grading system to evaluate objectively the strength of pre-clinical data of acute neuroprotective therapies for clinical translation in spinal cord injury. J Neurotrauma 2011; 28: 1525-1543.

16 Kwon BK, Soril LJ, Bacon M, Beattie MS, Blesch A, Bresnahan JC et al. Demonstrating efficacy in preclinical studies of cellular therapies for spinal cord injury - how much is 
enough? Exp Neurol 2013; 248: 30-44. Erratum in: Exp Neurol. 2013;248: 299-300.

17 Khangura S, Konnyu K, Cushman R, Grimshaw J, Moher D. Evidence summaries: the evolution of a rapid review approach. Syst Rev 2012; 1: 10 .

18 Greenhalgh T. Papers that summarise other papers (systematic reviews and metaanalyses). BMJ 1997; 315: 672-675.

19 Bragge P. Asking good clinical research questions and choosing the right study design. Injury 2010; 41S: S3-S6.

20 Shea BJ, Grimshaw JM, Wells GA, Boers M, Andersson N, Hamel C et al. Development of AMSTAR: a measurement tool to assess the methodological quality of systematic reviews. BMC Med Res Methodol 2007; 7: 10

21 Shea BJ, Bouter LM, Peterson J, Boers M, Andersson N, Ortiz Z et al. External validation of a measurement tool to assess systematic reviews (AMSTAR). PLoS One 2007; 2: e1350.

22 Shea BJ, Hamel C, Wells GA, Bouter LM, Kristjansson E, Grimshaw J et al. AMSTAR is a reliable and valid measurement tool to assess the methodological quality of systematic reviews. J Clin Epidemiol 2009; 62: 1013-1020.

23 Noyes J, Popay J, Pearson A, Hannes K, Booth A. On behalf of The Cochrane Qualitative Research Methods Group. Chapter 20: Qualitative research and Cochrane reviews. In Higgins J, Green S, eds. Cochrane Handbook for Systematic Reviews of Interventions, Version 5.1.0 [updated March 2011] Available from www.cochrane-handbook.org. The Cochrane Collaboration 2011

24 Lewin S, Oxman AD, Lavis JN, Fretheim A. SUPPORT Tools for evidence-informed health Policymaking (STP) 8: deciding how much confidence to place in a systematic review. Health research policy and systems/ BioMed Central 2009; 7 (Suppl 1): S8.

25 Simpson LA, Eng JJ, Hsieh JT, Wolfe DL. The health and life priorities of individuals with spinal cord injury: a systematic review. J Neurotrauma 2012; 29: 1548-1555.

26 Hammell KW. Quality of life after spinal cord injury: a meta-synthesis of qualitative findings. Spinal Cord 2007; 45: 124-139.

27 Ditunno PL, Patrick M, Stineman M, Ditunno JF. Who wants to walk? Preferences for recovery after SCl: a longitudinal and cross-sectional study. Spinal Cord 2008; 46: 500-506.

28 Hampton NZ, Qin-Hilliard DB. Dimensions of quality of life for Chinese adults with spinal cord injury: a qualitative study. Disabil Rehabil 2004; 26: 203-212.

29 Nagarajan G, Arumugam E, Tharion G, Bhattacharji S. Perceptions of patients with spinal cord injury on future research in South India. Social Care and Neurodisability 2012; 3: 20-26.

30 Anderson KD. Targeting recovery: priorities of the spinal cord-injured population. J Neurotrauma 2004; 21: 1371-1383.

31 Anderson KD, Friden J, Lieber RL. Acceptable benefits and risks associated with surgically improving arm function in individuals living with cervical spinal cord injury. Spinal Cord 2009; 47: 334-338.

32 Backman C, Forwell SJ, Carpenter C, Jongbloed L. Priority issues for British Columbians living with spinal cord injury. Int J Disabil Community Rehabil 2007; http://www.ijdcr. caNOL06 01 CAN/articles/backman.shtml.

33 Benony H, Daloz L, Bungener C, Chahraoui K, Frenay C, Auvin J. Emotional factors and subjective quality of life in subjects with spinal cord injuries. Am J Phys Med Rehabil 2002; 81: 437-445.

34 Bloemen-Vrencken JH, Post MW, Hendriks JM, De Reus EC, De Witte LP. Health problems of persons with spinal cord injury living in the Netherlands. Disabil Rehabil 2005; $27:$ 1381-1389.

35 Boschen KA. Measuring quality of life of adults with spinal cord injuries: Lessons for developmental disabilities research. J Dev Disabil 1997; 5: 91-95.

36 Boswell BB. Exploring quality of life of adults with spinal cord injuries. Percept Mot Skills 1997; 84: 1149-1150.

37 Brown-Triolo DL, Roach MJ, Nelson K, Triolo RJ. Consumer perspectives on mobility: implications for neuroprosthesis design. J Rehabil Res Dev 2002; 39: 659-669.

38 Cox RJ, Amsters DI, Pershouse KJ. The need for a multidisciplinary outreach service for people with spinal cord injury living in the community. Clin Rehabil 2001; 15: 600-606.

\section{APPENDIX 1}

\section{Medline search strategy to identify Systematic Reviews of research priorities in spinal cord injury}

1. exp Spinal Cord Injuries/

2. spinal cord injur ${ }^{\star} . \mathrm{mp}$. [ $\mathrm{mp}=$ title, abstract, original title, name of substance word, subject heading word, keyword heading word, protocol supplementary concept, rare disease supplementary concept, unique identifier]

3. research priorit ${ }^{\star} . \mathrm{mp}$. [ $\mathrm{mp}=$ title, abstract, original title, name of substance word, subject heading word, keyword heading word, protocol supplementary concept, rare disease supplementary concept, unique identifier]

4. priority setting.mp. ( $\mathrm{mp}=$ title, abstract, original title, name of substance word, subject heading word, keyword heading word, protocol supplementary concept, rare disease supplementary concept, unique identifier]

5. 1 or 2

6. 3 or 4

7. 5 and 6
39 Cushman LA, Scherer MJ. A pilot study of perceived needs of persons with new spinal cord injury. Psychol Rep 2002; 90: 1153-1160. Spinal-Cord Injured Males. Arch Phys Med Rehabil 1976; 57: 291-293.

Kannisto M, Merikanto J, Alaranta H, Hokkanen H, Sintonen H. Comparison of Cord 1998. 36: 193-199.

42 Kennedy P, Lude P, Taylor N. Quality of life, social participation, appraisals and coping post spinal cord injury: a review of four community samples. Spinal Cord 2006; 44 95-105.

3 Kennedy P, Rogers B. Reported quality of life of people with spinal cord injuries: a longitudinal 503.

4 Lin KH, Chuang CC, Kao MJ, Lien IN, Tsauo JY. Quality of life of spinal cord injured patients in Taiwan: a subgroup study. Spinal Cord 1997; 35: 841-849.

Laman H, Lankhorst GJ. Subjective weighting of disability:an approach to quality-of-life assessment in rehabilitation. Disabil Rehabil 1994; 16: 198-204.

6 Snoek GJ, IJzerman MJ, Hermens HJ, Maxwell D, Biering-Sorensen F. Survey of the fortinal cord injury: impact and priority for improvement in hand function in tetraplegics. Spinal Cord 2004; 42: 526-532.

(J)erman MJ, Post MW, Stiggelbout AM, Roach MJ, Zilvold G. compared with other impairments in tetraplegia. Arch Phys Med Rehabil 2005; 86 1630. (o improve upper-extremity function. J Hand Surg Am 2007; 32 shifting among long-term spinal cord injury survivors. Brit J Health Psych 2000; 5

50 White MJ, Rintala DH, Hart KA, Young ME, Fuhrer MJ. Sexual activities,

51 White MJ, Rintala DH, Hart KA, Fuhrer MJ. Sexual activities, concerns and interests of women with spinal cord injury living in the community. Am J Phys Med Rehabil 1993; 72: 372-378.

Yerxa EJ, Locker SB. Quality of time use by adults with spinal cord injuries. Am J Occup

Boswell BB, Dawson M, Heininger E. Quality of life as defined by adults with spinal cord injuries. J Rehabil 1998; 64: 27-32.

Carpenter C. The experience of spinal cord injury: the individual's perspective: implications for rehabilitation practice. Phys Ther 1994; 74: 614-629.

6 Duggan $\mathrm{CH}$, Dijkers M. Peaks and valleys: a qualitative analysis of the narratives of .

( paraplegic spinal cord injury. Qual Health Res 2001; 11: 795-811. narrative types. Disab Soc 2004; 19: 613-626. community. Spinal Cord 2004; 42: 607-620.

60 Bragge P, Piccenna L, Middleton J, Williams S, Creasey G, Dunlop S et al. Developing a spinal cord injury research strategy using a structured process of evidence wiew and stakeholder dialogue. Part II: background to a research strategy. Spinal Cord (doi:10.1038/sc.2015.86)

Middleton JW, Piccenna L, Gruen RL, Williams S, Creasey G, Dunlop S et al. oping a spinal cord injury research strategy using a structured process of evidence review and stakeholder dialogue. Part III: outcomes. Spinal Cord (doi:10.1038/ sc.2015.87). 71: 225-231. Ther 1990; 44: 318-326. 


\section{APPENDIX 2 SYSTEMATIC REVIEW QUALITY APPRAISAL CRITERIA AND FINDINGS}

\begin{tabular}{lll} 
Criteria (SUPPORT tooR4_qualitative studies) & HammelR6 & Criteria (AMSTAR 22 quantitative studies) \\
\hline 1. Did the review address an appropriate policy or management question? & Yes & 1. Was 'a priori' design provided? \\
$\begin{array}{lll}\text { 2. Were the criteria used to select studies appropriate? } & \text { Yes } & \text { 2. Was there duplicate study selection and data extraction? } \\
\text { 3. Was a clear and appropriate explanation provided for the search } & \text { Yes } & \text { 3. Was a comprehensive literature search performed? }\end{array}$
\end{tabular}

approach used?

4. Was the approach used to assess the reliability of the included Yes studies appropriate?

5. Was an appropriate approach used to analyse the findings of the included studies?
Yes

4. Was the status of publication (i.e., grey literature) used as an inclusion criterion?

Yes

5. Was a list of studies (included and excluded) provided?

6. Were the characteristics of the included studies provided?

7. Was the scientific quality of the included studies assessed and documented?

8. Was the scientific quality of the included studies used appropriately in formulating conclusions?

9. Were the methods used to combine the findings of studies appropriate?

10. Was the likelihood of publication bias assessed?

11. Was the conflict of interest included?
Simpson

Yes

No

No

Yes

No

No

N/A

No

No
Quality appraisal summary

The overall quality of this meta-synthesis was high. The author used an appropriate approach to assess the reliability of and to analyse the findings of the included studies. All the key methodological information was reported, allowing reproducibility for other researchers in the field.
The overall quality of the SR was assessed as low to moderate. Although a comprehensive search of the literature was conducted with independent study selection/data extraction, the quality of the included studies was not assessed or documented and hence not used in formulating overall conclusions.

APPENDIX 3 INCLUDED STUDIES BY STUDY TYPE AND STAKEHOLDERS INVOLVED

\begin{tabular}{|c|c|c|}
\hline Citation & Data collection method $(\mathrm{n})$ & Stakeholders \\
\hline \multicolumn{3}{|l|}{ Included in Simpson et al. ${ }^{25}$} \\
\hline Anderson ${ }^{30}$ & Survey (681) & People with SCI (Tetra \& Para) \\
\hline Anderson et al. ${ }^{31}$ & Web-based survey (137) & People with SCI (Tetra only) \\
\hline Backman et al..$^{32}$ & Survey (357) & People with SCI (Tetra \& Para) \\
\hline Benony et al.33 & Interview (66; $33 \mathrm{SCl}, 33$ controls) & People with SCI (Tetra \& Para) \\
\hline Bloemen-Vrencken et al. ${ }^{34}$ & Survey (454) & People with SCI (Tetra \& Para) \\
\hline Boschen ${ }^{35}$ & Not available & Not available \\
\hline Boswell ${ }^{36}$ & Survey (12) & People with SCI (Tetra \& Para) \\
\hline Brown-Triolo et al. ${ }^{37}$ & Telephone interview (94) & People with SCI (Para only) \\
\hline Cox et al. ${ }^{38}$ & Interview (60) & People with SCI (Tetra \& Para) \\
\hline Cushman and Scherrer ${ }^{39}$ & Survey (22) & People with SCI (NS) \\
\hline Ditunno et al. ${ }^{27}$ & Panels (51) & People with SCI (Tetra \& Para) \& Health Professionals ( 5 acute, 5 rehabilitation clinicians, 5 other) \\
\hline Hanson and Franklin 40 & NS (15) & People with SCI (Tetra \& Para) \\
\hline Kannisto et al. ${ }^{41}$ & Interview (101) & People with SCI (Tetra \& Para) \\
\hline Kennedy et al. ${ }^{42}$ & Survey (350) & People with SCI (Tetra \& Para) \\
\hline Kennedy and Rogers ${ }^{43}$ & Survey (24) & People with SCl (Tetra \& Para) \\
\hline Lin et al. ${ }^{44}$ & Survey (347) & People with SCl (Tetra \& Para) \\
\hline Laman and Lankhorst. 45 & Survey (25) & People with $\mathrm{SCl}(\mathrm{NS})$ \\
\hline Snoeke et al. ${ }^{46}$ & Survey (565) & People with SCI (Tetra only) \\
\hline Snoek et al. ${ }^{47}$ & Interview (47) & People with SCI (Tetra only) \\
\hline Wagner 48 & Survey $(50)$ & People with SCI (Tetra only) \\
\hline
\end{tabular}




\begin{tabular}{|c|c|c|}
\hline Weitzenkamp et al. ${ }^{49}$ & Survey (195) & People with SCI (Tetra \& Para) \\
\hline White et al. ${ }^{50}$ & Survey (79) & Men with $\mathrm{SCl}$ \\
\hline White et al. ${ }^{51}$ & Survey $(40)$ & Women with $\mathrm{SCl}$ \\
\hline Yerxa and Locker ${ }^{52}$ & Log (27; $15 \mathrm{SCl}, 12$ matched controls) & People with SCI (NS) \\
\hline \multicolumn{3}{|l|}{ Included in HammelR6 } \\
\hline Bach and McDaniel $\left.\right|^{53}$ & Focus group (14) & People with SCI (Tetra only) \\
\hline Boswell et al. ${ }^{54}$ & Focus group (12) & People with SCI (Tetra \& Para) \\
\hline Carpenter ${ }^{55}$ & Interview (10) & People with SCI (Tetra \& Para) \\
\hline Duggan et al. ${ }^{56}$ & Interview (40) & People with SCl (NS) \\
\hline Manns and $\mathrm{Chad}^{57}$ & Interview (15) & People with SCI (Tetra \& Para) \\
\hline Smith and Sparkes ${ }^{58}$ & Interview (14) & Men with SCl \\
\hline Hammell 59 & Interview (15) & People with SCI (Tetra \& Para) \\
\hline
\end{tabular}

Key: NS, not specified; Para, paraplegia; Tetra, tetraplegia 